\title{
INFLUENCE OF TOOL CLAMPING ON TOOL WEAR
}

\author{
Marek Vozár, Boris Pätoprstý, Vladimír Šimna, Jozef Peterka
}
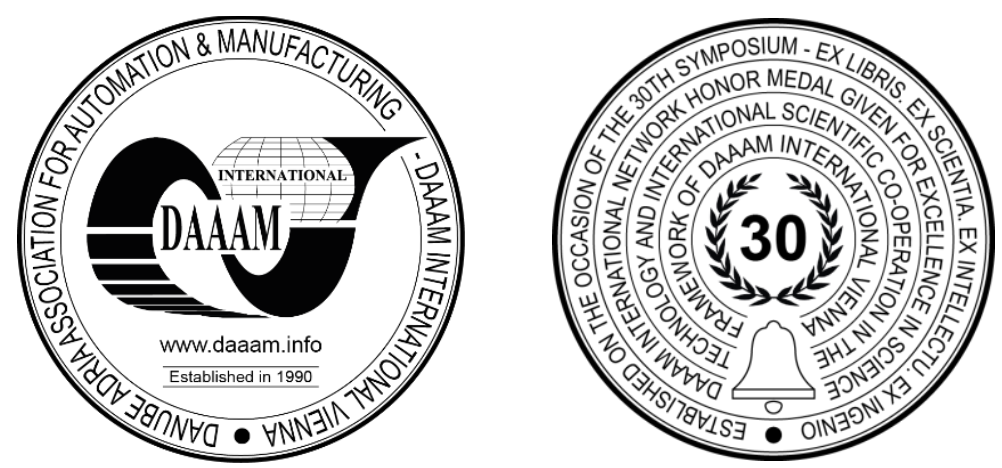

This Publication has to be referred as: Vozar, M[arek]; Patoprsty, B[oris]; Simna, V[ladimir] \& Peterka, J[ozef] (2019). Influence of Tool Clamping on Tool Wear, Proceedings of the 30th DAAAM International Symposium, pp.0782-0786, B. Katalinic (Ed.), Published by DAAAM International, ISBN 978-3-902734-22-8, ISSN 1726-9679, Vienna, Austria DOI: $10.2507 / 30$ th.daaam.proceedings. 108

\begin{abstract}
The paper deals with the problem of clamping shank tools in conventional milling operations and how it influences tool wear and tool life. In the experiment, four different types of clamps were used - spring collet, shrink fit tool holder and two hydraulic chucks. Tools used for the experiment were uncoated monolithic solid carbide end mills. For every clamping setup, tool wear tests were carried out, and times it took to reach set value of wear were measured. Time values were compared to determine how the clamping mechanism can influence tool wear, as well as what clamping method produced the best results. Aim of the research was to measure the influence of tool clamping on tool wear. It was discovered that the best tool life was achieved with the spring collet, and worst with hydraulic chuck.
\end{abstract}

Keywords: milling; tool clamping; solid carbide mills; tool life; tool wear

\section{Introduction}

Choice of tool clamping solution is one of the links in the machine tool - workpiece interaction that can get easily overlooked, especially when dealing with conventional machining [1]. Clamping system should be sufficiently rigid, while efficiently transferring the torque from the spindle to the tool [2]. Vibrations of the tool during the milling process are common cause of increased tool wear, therefore clamping system should work to damp the vibrations [3,4]. Another aspect to consider might be safety or ergonomics of the tool clamps, because it's one of the parts of the machine tool that the workers often handle manually [5]. There is variety of different tool clamping systems made by various manufacturers, for universal applications, as well as specialized ones [6], meanwhile, new clamping solutions are being actively developed as well [7]. Every clamping system has a set of parameters that should determine its use for a specific application, however, the effect of the tool clamping on the tool wear has not been given due consideration, in contrast with the workpiece clamping solutions $[8,9,10]$. One of the main areas where tool clamping is especially important is when machining with tools with long overhang [11]. Since tool clamping can affect the productivity and economy of the manufacturing process, highlighting its importance in relation to the technology of milling should be in order [12]. In the experiment described in the article, four different types of tool clamping solutions were used and tool wear was measured during the machining process. Measured factor of wear was average flank wear width (VB), with the $\mathrm{VB}_{\max }$ value set to $0,3 \mathrm{~mm}$. 


\section{Materials and methods}

Materials, equipment and machinery used for the experiment are described in this section.

Tools used for the experiment were monolithic solid carbide mills that were manufactured from solid carbide rods on the Reinecker WZS60 tool grinding machine in the Centre of Excellence of 5-axis Machining at the Faculty of Materials Science and Technology of Slovak Technical University. Specific grade of the cemented carbide was PCG F10 that is equivalent to K20-K30 by ISO. Detailed material specifications can be found in Table 1 [13].

\begin{tabular}{|c|c|c|c|c|l|}
\hline PCG Grade & ISO group & Co volume & $\begin{array}{l}\text { Hardness } \\
\text { HV30 }\end{array}$ & Hardness HRA & Density \\
\hline F10 & K20-K30 & $10 \%$ & 1580 & 92,0 & $14,35 \mathrm{~kg} . \mathrm{m}^{-3}$ \\
\hline
\end{tabular}

Table 1. Tool material specifications [13]

\begin{tabular}{|l|c|}
\hline Tool parameter & Value \\
\hline Cutting diameter & $9,9 \mathrm{~mm}$ \\
\hline Maximum depth of cut & $20 \mathrm{~mm}$ \\
\hline Tool length & $85 \mathrm{~mm}$ \\
\hline Shank diameter & $10 \mathrm{~mm}$ \\
\hline Center diameter & $5 \mathrm{~mm}$ \\
\hline Cutting edge count & 3 \\
\hline Flute helix angle & $45^{\circ}$ \\
\hline Rake angle $\gamma$ & $10^{\circ}$ \\
\hline Flank angle $\alpha 1$ & $12^{\circ}$ \\
\hline
\end{tabular}

Table 2. Tool parameters

Material of the machined workpiece used for the tool wear test was medium carbon steel grade C45 ISO 683-1:2018, with dimensions of 140x140x100 mm.

\begin{tabular}{|l|l|l|l|l|l|l|l|}
\hline \multicolumn{7}{|c|}{ Chemical composition (\%) } \\
\hline $\mathbf{C}$ & $\mathbf{M n}_{\max }$ & $\mathbf{S i}_{\max }$ & $\mathbf{P}_{\max }$ & $\mathbf{S}_{\max }$ & $\mathbf{C r}_{\max }$ & $\mathbf{N i}_{\max }$ & $\mathbf{M o}_{\max }$ \\
\hline $0,42-0,50$ & $0,50-0,80$ & 0,40 & 0,045 & 0,045 & 0,40 & 0,40 & 0,10 \\
\hline
\end{tabular}

Table 3. Workpiece material chemical composition

Four different clamping systems were used in order to compare their influence on the machining process and resulting tool wear.

\begin{tabular}{|l|l|l|l|}
\hline Clamp type & Manufacturer & Runout [mm] & Length [mm] \\
\hline Spring collet TYP 5675 & SECO & $\max 0.01$ & 100 \\
\hline Shrink fit tool holder SFD 10x120 & SECO & $\max 0.003$ & 120 \\
\hline Hydraulic chuck CoroChuck 930 & Sandvik Coromant & $\max 0.003$ & 100 \\
\hline Hydraulic chuck TENDO E Compact 206406 & Schunk & $\max 0.003$ & 80 \\
\hline
\end{tabular}

Table 4. Basic parameters of clamps used for the experiment

Digital optical microscope Dino-lite was used to observe and measure the tool wear. For every clamping system, tool wear tests with identical constant cutting parameters were carried out.

\begin{tabular}{|l|l|}
\hline Parameter & Value \\
\hline Cutting speed & $100 \mathrm{~m} \cdot \mathrm{min}^{-1}$ \\
\hline Feed per tooth & $0.03 \mathrm{~mm}$ \\
\hline Feed rate & $280 \mathrm{~m} \cdot \mathrm{min}^{-1}$ \\
\hline Axial depth of cut & $0.5 \mathrm{~mm}$ \\
\hline Radial depth of cut & $5 \mathrm{~mm}$ \\
\hline Tool overhang & $38 \mathrm{~mm}$ \\
\hline
\end{tabular}

Table 5. Cutting parameters of the tool wear tests 
Cutting fluid was not used in the tests, tools were air cooled only. Linear NC paths were generated in the CAM software Autodesk Powermill. Tools were measured after one minute of milling, subsequently tools were measured in five minute intervals during milling. Tool wear criterion $\mathrm{VB}_{\max }$ was set for $0.3 \mathrm{~mm}$, this value was reached after 41 minutes of machining.

\section{Results and discussion}

In the graph on Figure 1, we can see the comparison of the development of values of VB in time. Tool clamped in hydraulic chuck Tendo E Compact was found out to last the least amount of machining time, as the set criterion of wear was reached most quickly. This result was used as a baseline for the other clamping types. Hydraulic chuck CoroChuck 930 has contributed to a minor improvement of the tool life, as the tool in this holder lasted 18 seconds more than with the aforementioned chuck. Tool in the shrink fit holder registered more substantial increase in the tool life, lasting 54 seconds more. Best result was achieved while using the spring collet, tool in this clamping system lasted 4 minutes 57 seconds longer. These time values are illustrated in the figure 2 .

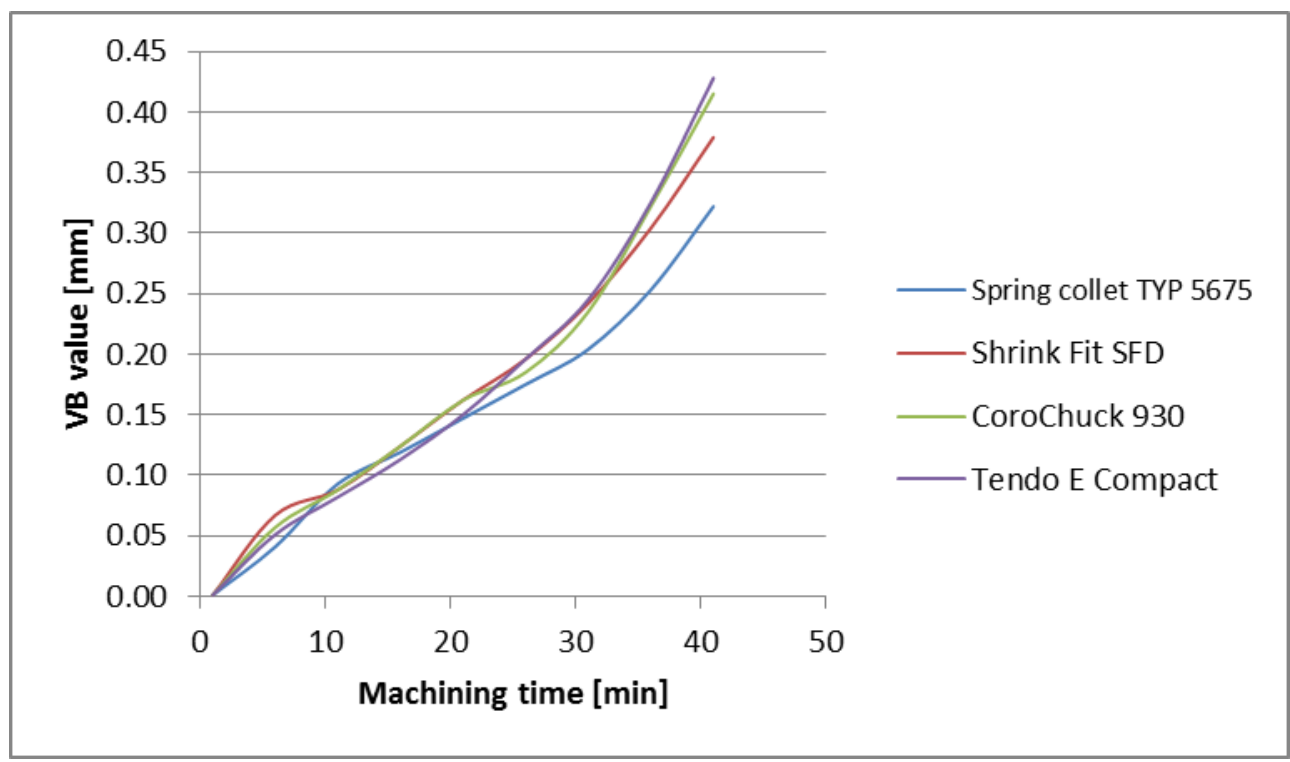

Fig. 1. Comparison of clamping systems in relation to the value of VB

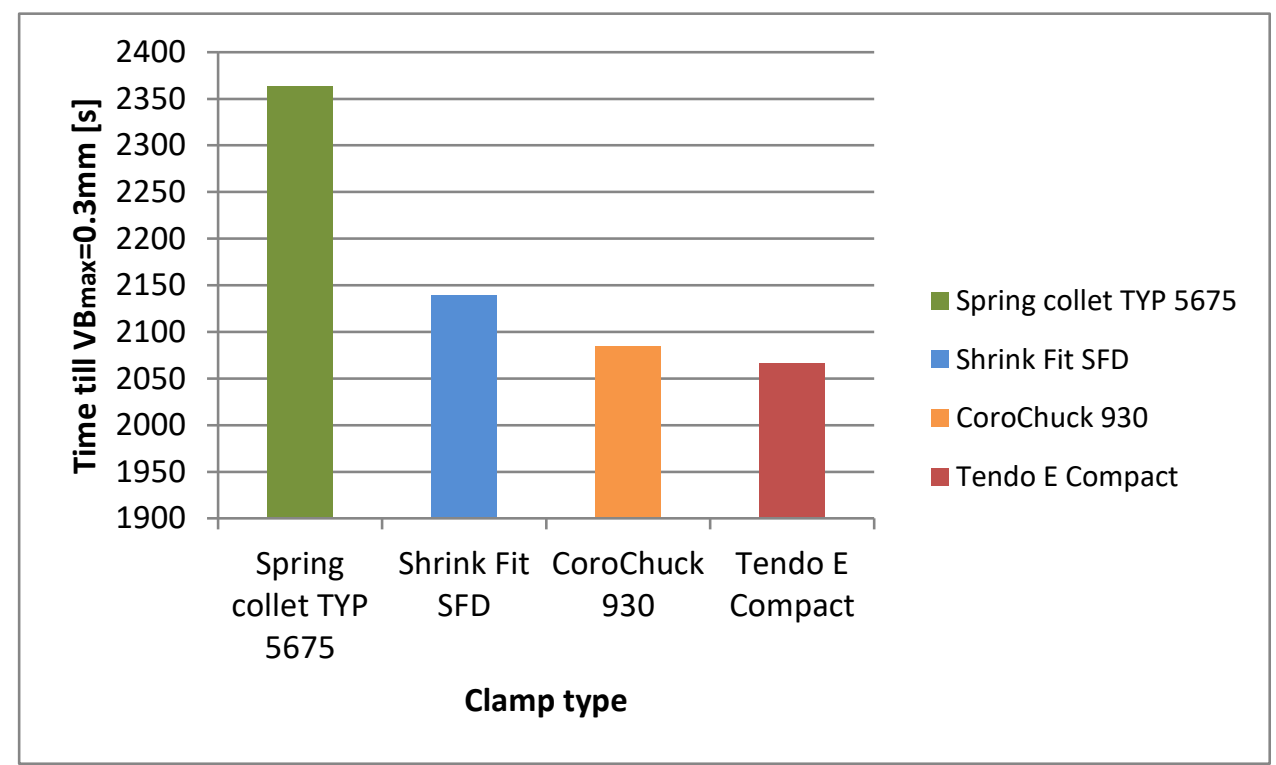

Fig. 2. Comparison of clamping systems in relation to the time

Table 6 contains differences in time in seconds it took for the tool in the specified holder to reach set criterion of VB critical. It can be noted that for a single tool life time, values nearing 5 minutes are significant from the standpoint of 
productivity in machining, since, extrapolating this time reduction in mass production can provide substantial manufacturing cost reduction.

\begin{tabular}{|l|r|r|r|r|}
\hline \multicolumn{1}{|c|}{ Clamp type } & $\begin{array}{l}\text { Spring collet } \\
\text { TYP 5675 }\end{array}$ & Shrink Fit SFD & CoroChuck 930 & $\begin{array}{l}\text { Tendo E } \\
\text { Compact }\end{array}$ \\
\hline $\begin{array}{l}\text { Spring collet } \\
\text { TYP 5675 }\end{array}$ & 0 & 165 & 279 & 297 \\
\hline Shrink Fit SFD & -165 & 0 & 54 & 72 \\
\hline CoroChuck 930 & -279 & -54 & 0 & 18 \\
\hline $\begin{array}{l}\text { Tendo E } \\
\text { Compact }\end{array}$ & -297 & -72 & -18 & 0 \\
\hline
\end{tabular}

Table 6. Tool life differences comparison in seconds

\section{Conclusion}

Purpose of the experiment that was carried out was to investigate the influence of tool clamping on tool wear. Based on the lower clamping force and higher runout for the spring collet, it could be assumed that the tool would wear out faster when clamped in this type of holder. Hydraulic chucks are generally considered to be the best option when it comes to tool holders, because of the higher clamping force, better vibration damping capabilities, as well as lower runout compared to other types of clamping solutions. However, based on the experiment results, these assumptions were not verified. According to the measured results, highest tool life was observed for the spring collet, slightly worse results were achieved for the shrink fit holder, where the tool lasted 3 minutes 45 seconds less than in the spring collet. Hydraulic chucks did not prove to have significantly positive influence on the tool wear, tool used with CoroChuck hydraulic chuck took 54 seconds less to reach the set tool wear criterion than the tool used with the shrink fit holder. Tool clamped in hydraulic chuck Tendo E compact lasted 18 seconds less than the aforementioned hydraulic chuck from different manufacturer.

These values obtained from the experiment indicate, that the claims of tool holder manufacturers about the positive influence of their clamping solution on the tool life might not always be true. It should be noted that these results were only achieved for specific cutting tools and cutting parameters, it is entirely possible that different conclusion could be reached if the variables of the experiment were modified. Although tool wear is definitely an issue to consider when choosing the proper tool clamping system, there are other aspects to take into account. Each clamping system has its advantages and disadvantages that can influence the productivity of the manufacturing process, so depending on the intended use, every type of clamping solution should be given due consideration in relation to the final desired outcome.

By conducting the experiment, we have determined the best available clamping system so that we can minimize the influence of clamping system on the machining process in the future experiments focused on the wear behavior of the solid carbide mills with prepared edges.

\section{Acknowledgments}

This work was supported by the Scientific Grant Agency of the Slovak Republic under the grant no. 1/0097/17 and the Slovak Research and Development Agency of the Slovak Republic under the Contract no. APVV-16-0057.

\section{References}

[1] Rivin, E. et Al. (2000). Tooling Structure: Interface between Cutting Edge and MachineTool. CIRP Annals Volume 49, Issue 2, 2000, Pages 591-634.

[2] Paul, P.S.; Lawrence, G.; Yadav, R. K.; Mohankrishnan, N. V.; Nair, N.; Vasanth, A. (2014). Analysis of Dynamic Characteristics of Boring Tool Holder. Procedia Materials Science. Volume 5, (2014), Pages 2283-2292

[3] Parus, A.; Hoffman, M.; Okulik, T. (2011). Suppression of the Work-Piece Vibrations in Milling Using Active Clamp System. Vibration Problems ICOVP 2011. Springer Proceedings in Physics, vol 139. Springer, Dordrecht

[4] Fu, Q.; Rashid, A.; Nicolescu, C. M. (2013). Improving machining performance against regenerative tool chatter through adaptive normal pressure at the tool clamping interface. Journal of Machine Engineering, Vol. 13, No. 1, 2013

[5] Jung, M-C.; Hallbeck, M. S. (2005). Ergonomic redesign and evaluation of a clamping tool handle. Applied Ergonomics 36 (2005) 619-624

[6] Shin, W-C.; Ro, S-K.; Park, H-W.; Park, J-K. (2009). Development of a micro/meso-tool clamp using a shape memory alloy for applications in micro-spindle units. International Journal of Machine Tools \& Manufacture 49 (2009) 579-585 
[7] Uhlmann, E.; Langmack, M.; Löwenstein A.; Oberschmidt D. (2011). New Hybrid Machine Tool with an Automated Clamping System for Drilling Micro Holes by Laser Helical Drilling and $\mu$ EDM. Proceedings of the euspen International Conference - Como - May 2011.

[8] Oravcova, J.; Javorova, A. \& Rieciciarova, E. (2011). Design of active parts in clamping mechanism. Annals of DAAAM for 2011 \& Proceedings of the 22nd International DAAAM Symposium, Volume 22, No. 1, ISSN 17269679 ISBN 978-3-901509-83-4, Editor B. Katalinic, Published by DAAAM International, Vienna, Austria, EU, 2011.

[9] Kostal, P.; Mudrikova, A.; Kerak, P. (2010). Clamping fixture for new paradigms of manufacturing. Annals of DAAAM \& Proceedings of the 21st International DAAAM Symposium. Volume 21, No.1, ISSN 1726-9679. 2010, p361-362. Editor B. Katalinic, Published by DAAAM International, Vienna, Austria, EU, 2010

[10] Koudela, L.; Kotlan, V. (2015). High-speed rotation induction heating in thermal clamping technology. Applied Mathematics and Computation 267 (2015) 445-455

[11] Hwang, H. Y.; Lee, H. G.; Lee, D. G. (2004). Clamping effects on the dynamic characteristics of composite machine tool structures. Composite Structures 66 (2004) 399-407

[12] Antil, P.; Budhiraja, A. 2013. A case study on tool \& fixture modification to increase the productivity and to decrease the rejection rate in a manufacturing industry. International Journal Of Advance Research In Science And Engineering, Vol. No.2, Issue No.9

[13] PCG Precision Carbide Germany. Catalogue for Carbide Rods. (2018). Available on the internet: http://www.pcggmbh.de/assets/skizze_281220181817332018-11_PCG-Katalog_en.pdf 